SHORT COMMUNICATION

\title{
OCCURRENCE OF RED THREAD DISEASE IN THE GRASSES OF HORTON PLAINS NATIONAL PARK
}

\author{
N.K.B. ADIKARAM*, ARUNA WEERASOORIYA and T.D. MAHALIYANAGE \\ Department of Botany, University of Peradeniya
}

(Received: 25 May 2001 ; accepted: 24 January 2002)

Key words: Horton Plains, red thread disease

In early 1998 unusual drying and withering of leaves of two pasture grass species, Pennisetum clandestinum and Pennisetum glabarum, were observed in the grasslands (elevation $2200 \mathrm{~m}$ ) of the Horton Plains National Park, Sri Lanka. The examination of affected leaves and associated fungal structures revealed the condition to be the red thread disease caused by Laetiseria fuciformis [McAlp.] Burds. The intensity of the disease increased during wet weather. The disease did not occur in Pennisetum clandestinum found at slightly lower elevations, for example in Ambewela $(2100 \mathrm{~m})$. This is the first report of the disease from Sri Lanka or any sub-tropical climate.

Red thread disease has been documented as a common malady of perennial turf grass (Lolium perenne) in temperate regions throughout the world. ${ }^{6}$ The disease has previously been reported from Australia, ${ }^{7} \mathrm{Canada}^{9}$, United States ${ }^{\mathrm{*}}$ and Europe including England, ${ }^{10}$ Netherlands and Ireland. The disease is also a common problem in red fescue (Festuca rubra L.) and perennial rye grass in Maryland, the United States. ${ }^{4}$ The typical symptoms are pale and shriveled appearance and the presence of pink, thread-like projections in the affected leaf. Grass exhibiting similar symptoms but lacking needle-like, red stromata has been referred to as 'pink patch' caused by Athelia fuciformis ${ }^{2}$ and several other basidiomycetes. ${ }^{6}$ There is a belief that other fungi may also be associated with the red thread disease in grass. ${ }^{9}$ Differentiation of basidiomycetes associated with red thread and pink patch disease has been attempted. ${ }^{8}$

The red thread disease has formerly been attributed to Corticium fuciforme (McAlp Wakef.).4,10 Several contradicting reports on the cause of the disease have made the aetiology complicated. Berkeley ${ }^{3}$ described a hyphomycete collected from cereals in Australia by Baron Von Mueller in 1865 and named the fungus Isaria fuciformis Berk. Additional reports of $I$. fuciformis as a pathogen of grass were provided from Ireland, England and Australia late in the century. In 1906, McAlpine in Australia finally recognized the fungus as a basidiomycete and assigned it to the

"Corresponding author 
genus Hypochnus as $H$. fuciformis (Berk.) McAlp. Wakefield ${ }^{10}$ described a similar fungus on grasses in England. After examination, she assigned the fungus to the genus Corticium; hence the causal organism of red thread disease was called C. fuciforme (Berk.) Wakef for more than 60 years. Burdsall ${ }^{2}$ re-examined the type materials and reassigned it to a new genus, Laetiseria, as L. fuciformis (McAlp.) Burds.

While the forest die-back phenomenon in the Horton Plains was investigated in a two year project during 1997-1999, we came across several diseased grass patches opposite the dormitories of the park. Later, grasses with similar symptoms were found in the open grassland too. The diseased grasses were examined in the field, the grass species involved and the symptoms exhibited were noted down. Representative specimens from diseased patches were collected and brought to the laboratories at the Department of Botany, University of Peradeniya, for detailed examination. At the laboratory, the surface scrapings, transverse sections, etc. obtained from diseased leaf and associated fungal structures were examined under a microscope and the observations were recorded. The length of 20 pink stromata collected was measured and the average was calculated. To culture the fungus, pink colour stromatal fragments or pieces $(5 \mathrm{~mm}$ X $5 \mathrm{~mm}$ ) were first surface sterilized with $10 \% \mathrm{NaOCl}$ for 2 minutes and then placed on Potato Dextrose Agar medium. After incubation for 5-7 days at $25^{\circ} \mathrm{C}$, the plates were examined. Using symptoms, morphological characteristics of the fungus on diseased leaf and culture, the causal agent was identified. The identity of the fungus and the disease was confirmed by the Plant Protection Division, CABI Biosciences, England. The disease and its spread was monitored during a period of 12 months in 1998-99 by regular field visits to Horton Plains and examination of samples of diseased plants. The Horton Plains comprise two dominant vegetation types, upper wet black patana vegetation and evergreen upper Montane rain forest or cloud forest. ${ }^{1}$ The forest which occupies about $50 \%$ of the total area of the park, mainly occurs on hill summits. The grassland on the lower slopes of summits, depressions and valleys comprise the other half. The climate is sub-tropical; with mean annual temperature of $15^{\circ} \mathrm{C}$ and average annual rainfall of $2050 \mathrm{~mm}$.

The affected pasture grass species, Pennisetum clandestinum (Poaceae = Graminae) and $P$. glabarum had dried and withered leaves, the tip of affected leaves often carried pink coloured, branched, gelatinous threads (Fig. 1). The examination of affected leaves and associated fungal structures revealed the condition to be the red thread disease caused by Laetiseria fuciformis [McAlp.] Burds. Several large patches of diseased grass were first observed in the open grassland opposite the dormitory and later in other areas of the open grassland.

Red thread symptoms appear on the leaf blade of susceptible grasses initially as water-soaked areas and these then wither giving a pale, shrivelled appearance. The fungus grew beyond the tip of the withered leaf blade to form pink, thread-like 
or antler-like projections. These were 1-2 $\mathrm{mm}$ thick and 2-12 $\mathrm{mm}$ long stromata containing mycelium which lack clamp connections. Diagnosis of the disease is easiest in later stages when infected leaves carry these pink structures. In culture the fungus formed pink, tufted, slow-growing, irregularly shaped colonies. The mycelium consisted mostly of stranded hyphae. Re-inoculation of the fungus into its original hosts was not attempted. The symptoms were very characteristic and prominent, therefore the diagnosis was straight forward. Koch's postulates were not considered necessary for confirmation of the causal agent. The fungus does not attack the root system. However, the disease can severely damage the foliar portions. The intensity of the disease increased during wet weather.

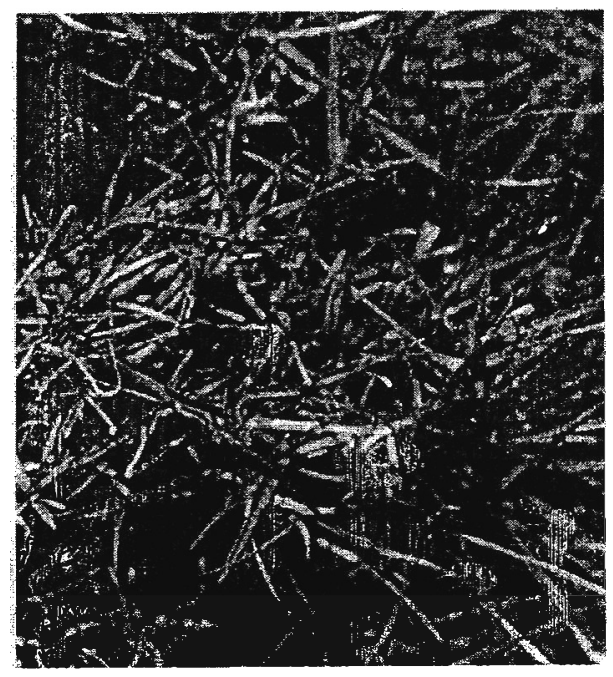

Figure 1: Pennisetum clandestinum affected by red thread disease (Note: the withered leaves, some containing pink, needle-like or antler-like fungal structures)

The severity of plant injury caused by red thread disease depends primarily on environmental conditions and vigor of susceptible plants. ${ }^{4}$ Low potassium, nitrogen and calcium levels in soil increase the incidence and severity of the disease. ${ }^{4}$

Some parts of the Horton Plains grassland had been used for potato cultivation during 1961-69 after removing natural grasses. Most of the low stature turf or pasture grasses widely growing now have been introduced accidentally with potato seed. The grasslands which have not been affected by potato cultivation are dominated by tussock or clump grasses such as Crysopogon zeylanicus and Garnotia tectorum. ${ }^{5}$ The two grass species affected by the disease appear to have been introduced with seed potato. The disease is restricted to the grasslands which had previously been used for potato cultivation. It is most likely that the red thread fungus would have also been introduced with the grass. The disease was not observed to be spreading 
rapidly at a threatening scale at present. However, the ability of the fungus to attack several turf and agricultural grass species, particularly in the cooler seasons and the gradual build up of innoculum in the currently affected areas can make the grassland in the Horton Plains vulnerable to the disease in any wet season.

\section{Acknowledgement}

Authors gratefully acknowledge Dr. J.M. Waller, CABI (Biosciences) for his assistance in diagnosis of the disease.

\section{References}

1 Balasubramaniam S., Ratnayake S. \& White R. (1993). The Montane forests of the Horton Plains Nature Reserve. Proceedings of the International and Interdisciplinary Symposium on Ecology and Landscape Management of Sri Lanka, 95-108.

2 Burdsall H.H. (1979). Laetiseria (Aphyllophorales, Corticiaceae), a new genus for the telemorph of Isaria fuciformis. Transactions of British Mycological Society 72:419-422.

3 Berkeley M.J. (1873). Australian fungi. Journal of Linnean Society 13: 175.

4 Cahill J.V., O’Neill N.R. \& Demoeden P.U. (1982). Variation among isolates of Corticium fuciforum causing red thread disease of turf grasses. Phytopathology 72: 932.

5 Gunatilleke C.V.S. (1996). A nature guide to the World's End trail, Horton Piains. Science Education Unit, University of Peradeniya, Sri Lanka 48pp.

6 Kaplan J.D. \& Jackson N. (1983). Red thread and pink patch diseases of turf grasses. Plant Disease 67: 159-162.

7 McAlpine D. (1906). A new hymenomycete - the so called Isaria fuciformis. Annals of Mycology 4: 541-551.

O'Neill N.R. (1983). Differentiation of basidiomycetes associated with red thread and pink patch disease in grasses. Phytopathology 73 (7): 1096.

9 Stapers J.A. and Loerakker, W.M. (1982). Laetiseria and Limnomyces species (Corticiaceae) causing pink diseases in turf grasses. Canadian Journal of Botany 60: 529-537.

10 Wakefield E.M. (1917). Notes on British Thelephoraceae. Transactions of the British Mycological Society 5: 474-481. 